\title{
Analisis Psikologi Tokoh dalam Naskah Drama Pinangan Karya Anton P. Chekhov Saduran Jim Lim Suyatna Anirun dengan Pendekatan Psikologi Analitis Carl Gustav Jung serta Implikasinya Terhadap Pembelajaran
}

\author{
Wildan Fauzi Mubarock ${ }^{1}$ \\ Viki Adiriyanto ${ }^{2}$ \\ 1, Pendidikan Bahasa dan Sastra Indonesia, FKIP UNPAK, Bogor \\ 2, Pendidikan Bahasa dan Sastra Indonesia, FKIP UNPAK, Bogor
}

\begin{abstract}
Literary works are very broad, and drama scripts are included. In general the drama script raised about the story of human life. The story of human life is played beautifully by each character. Each character has their own psychology which describes the personality structure that exists in him. This paper will examine the characters in the drama script Pinangan by Anton P. Chekhov adaptation of Jim Lim Suyatna Anirun based on aspects of Carl Gustav Jung's Analytical Psychology. The focus of this research is to analyze the psychology of the main character in the script play Pinangan by Anton P. Chekhov adaptation of Jim Lim Suyatna Anirun with Carl Gustaf Jung's Analytical Psychological approach and its implications for learning Indonesian in high school. The purpose of this study is to determine the psychology that exists in the main character and its implications in learning Indonesian. This shows that the conflict in the story presented in the drama script is about love and debate, and no one wants to reduce their egos in dealing with every problem that comes. Thus, it can be concluded that the main character of the drama script Pinangan is a person who has a personality structure according to Carl Gustav Jung's Analytical Psychological theory. The implications of the Pinangan drama script in Indonesian language learning are contained in the basic competencies of 3.18 and 4.182013 curriculum which emphasizes that students can show one of the characters in a drama that is read or watched orally in a literary work, this is in accordance with the personality of the main character that is very unique and interesting for students to play and to hone the acting talent in students.
\end{abstract}

Keywords: drama script, analytical psychology, personality structure

\begin{abstract}
ABSTRAK
Karya sastra sangatlah luas, dan naskah drama termasuk ke dalamnya. Pada umumnya naskah drama mengangkat tentang kisah kehidupan manusia. Kisah kehidupan manusia tersebut diperankan secara apik oleh setiap tokohnya. Setiap tokoh memiliki psikologinya masing-masing yang menggambarkan struktur kepribadian yang ada pada dirinya. Tulisan ini akan mengkaji tokoh dalam naskah drama Pinangan karya Anton P. Chekhov saduran Jim Lim Suyatna Anirun berdasarkan aspek Psikologi Analitis Carl Gustav Jung. Fokus penelitian ini yaitu menganalisis psikologi yang ada pada diri tokoh utama dalam naskah drama Pinangan karya Anton P. Chekhov saduran Jim Lim Suyatna Anirun dengan pendekatan Psikologi Analitis Carl Gustaf Jung serta implikasinya terhadap pembelajaran bahasa Indonesia di SMA. Tujuan penelitian ini untuk mengetahui psikologi yang ada pada diri tokoh utama serta implikasinya dalam pembelajaran bahasa Indonesia. Hal ini menunjukkan bahwa konflik cerita yang tersaji dalam naskah drama tersebut yaitu mengenai kisah cinta dan perdebatan, serta tak ada yang mau menurunkan ego masing-masing dalam menghadapi setiap permasalahan yang datang. Dengan demikian, dapat disimpulkan bahwa tokoh utama naskah drama Pinangan merupakan pribadi yang memiliki struktur kepribadian sesuai teori Psikologi Analitis Carl Gustav Jung. Implikasi naskah drama Pinangan dalam pembelajaran bahasa Indonesia tertuang dalam kompetensi dasar 3.18 dan 4.18 kurikulum 2013 yang menekankan agar siswa dapat mempertunjukkan salah satu tokoh dalam drama yang dibaca atau ditonton secara lisan pada suatu karya sastra, hal ini sesuai dengan kepribadian pada tokoh utama yang sangat unik dan menarik untuk siswa perankan serta untuk mengasah bakat akting pada diri siswa.
\end{abstract}

Kata Kunci: naskah drama, psikologi analitis, struktur kepribadian 


\section{PENDAHULUAN}

Karya sastra merupakan bentuk karya tulis paling indah yang pernah dibuat oleh manusia. Bukan hanya indah dari segi tulisan saja, melainkan dari makna yang terkandung dalam karya sastra tersebut. Karya sastra dicipta dari pemikiran dan perasaan pengarangnya dengan objek kajiannya adalah keadaan lingkungan sekitar tentang permasalahan-permasalahan yang sedang terjadi dan atau sudah terjadi. Karya sastra terdapat berbagai jenis, di antaranya adalah puisi, cerpen, novel, dan drama. Karya sastra tersebut tidak dapat dipisahkan dari permasalahan-permasalahan yang sedang terjadi dan atau sudah terjadi.

Membincangkan karya sastra, drama adalah karya sastra yang sarat akan realitas dibalut muatan fiksi yang menarik dan sangat unik lagi kreatif saat dipentaskan. Drama memiliki beberapa unsur, salah satunya yaitu naskah drama. Naskah drama yaitu percakapan antar dua orang atau lebih untuk menggambarkan alur sebuah cerita dari awal hingga akhir sebuah pementasan drama. Tokoh menjadi sosok sentral dalam dialog-dialog yang dilontarkannya.

Naskah drama menjadi suatu karya sastra yang menonjolkan sifat dan karakter tokohtokohnya. Salah satu contohnya adalah naskah drama Pinangan karya Anton P. Chekhov yang telah disadur oleh Jim Lim Suyatna Anirun. Naskah drama tersebut berasal dari Rusia, tapi karena keunikan naskah drama tersebut akhirnya Jim Lim Suyatna Anirun seorang penggiat teater asal Indonesia tertarik untuk menyadurnya yang kemudian dipentaskan di negara Indonesia.

Naskah drama Pinangan saduran Jim Lim Suyatna Anirun adalah drama satu babak yang diperankan oleh tiga tokoh di dalamnya. Agus Tubagus sebagai tokoh utama, lalu ada Ratna Rukmana Kholil dan Raden Rukmana Kholil sebagai peran pendukung tokoh utama. Agus Tubagus adalah pemuda kaya raya yang memiliki tujuan baik untuk melamar Ratna Rukmana. Karena ego sudah berkuasa diantara kedua belah pihak akhirnya terjadilah permasalahan-permasalahan yang muncul antara Agus Tubagus dengan Ratna Rukmana yang dibantu Ayahnya bernama Rukmana
Kholil menjadi acara pertengkaran perebutan hak milik tanah dan adu kehebatan anjing.

Sifat dan psikologi tokoh Agus Tubagus yang uniklah akhirnya menjadi hal yang tertarik untuk penulis teliti. Dalam kehidupan ini banyak sekali kita temui sifat dan karakter setiap orang yang berbeda-beda. Dengan mempelajari dan mendalaminya lewat peran tokoh Agus Tubagus dalam naskah drama Pinangan karya Anton P. Chekhov diharapkan memberi ilmu yang bermanfaat bagi pembaca, khususnya dalam hal yang menyangkut sifat dan psikologi manusia.

Hubungan antara hal yang telah dipaparkan dengan pembelajaran di SMA ada pada kompetensi inti tiga, yaitu memahami pengetahuan (faktual, konseptual, dan prosedural) berdasarkan rasa ingin tahunya tentang ilmu pengetahuan, teknologi, seni, budaya terkait fenomena dan kejadian tampak mata. Naskah drama ini adalah salah satu dari banyaknya naskah drama yang dapat memberikan pengetahuan bagi peserta didik SMA. Selaras dengan hal tersebut, peneliti tertarik untuk menganalisis psikologi tokoh Agus Tubagus dalam naskah drama Pinangan karya Anton P. Chekhov menggunakan pendekatan psikologi analitis Carl Gustav Jung serta implikasinya terhadap pembelajaran Bahasa Indonesia di SMA.

\section{LANDASAN TEORI}

\section{Drama}

Drama adalah bagian dari karya sastra. Poerwadarminta (2012: 258), berpendapat bahwa kata drama berarti cerita sandiwara yang mengharukan atau lakon sedih. Sedangkan Ferdinan Bruetiere dan Balthazar Vergehen (dalam Hasanuddin, 2015: 2) menyatakan bahwa drama adalah kesenian yang melukiskan sikap dan sifat manusia dengan action dan perilaku. Dikuatkan pula oleh A. Kaliun Ahmad (dalam Tamsin dan Amir, 2003: 15) menyatakan bahwa drama merupakan suatu hasil karya cipta yang seni medianya berbentuk cerita yang diperagakan penonton. Dari berbagai pendapat ahli di atas dapat disimpulkan bahwa drama tidak hanya menyajikan komedi dan tragedi saja, 
pementasan drama juga memiliki makna yang ingin disampaikan kepada penonton dengan menampilkan cerita kehidupan manusia yang diperagakan oleh gerakan dan dialog para tokohnya.

\section{Psikologi analitis Carl Gustav Jung}

Carl Gustav Jung merupakan salah satu pakar psikologi analitis yang juga membahas mengenai kepribadian. Menurut Jung kepribadian tersimpan dalam wilayah kesadaran dan ketidaksadaran, kepribadian yang dimiliki seseorang dipengaruhi oleh pengalaman. Carl Gustav Jung membagi teorinya menjadi dua bagian yaitu kesadaran dan ketidaksadaran, kesadaran mempunyai dua hal penting yaitu fungsi jiwa dan sikap jiwa sedangkan ketidaksadaran juga dibagi kedalam dua bagian yaitu ketidaksadaran personal dan ketidaksadaran kolektif.

Jung berpendapat bahwa manusia tidak boleh meninggalkan kepercayaan terhadap arketipe yang dibentuk oleh warisan (Hidayat, 2011: 4243). Maka secara garis besar dari teori Carl Gustav Jung adalah kepribadian seseorang dan Jung membagi kepribadian itu menjadi dua bagian yaitu alam kesadaran dan alam ketidaksadaran. Kesadaran mempunyai dua komponen pokok yaitu fungsi jiwa dan sikap jiwa, yang masing-masing mempunyai peranan penting dalam orientasi manusia dalam dunianya, sedangkan ketidaksadaran juga dibagi ke dalam dua bagian yaitu ketidaksadaran personal dan ketidak sadaran kolektif.

Jung merumuskan ketidaksadaran kolektif sebagai suatu warisan kejiwaan yang besar dari perkembangan kemanusiaan, yang terlahir kembali dalam struktur tiap-tiap individu, dan membandingkannya dengan apa yang disebut oleh Levy Bruhl tanggapan mistik kolektif (representations collective) orang-orang primitif (Suryabrata, 2014: 167). Menifestasi dari ketidaksadaran kolektif ini berupa mimpi, fantasi, khayalan, dan arketipe. Psikologi analitis Carl Gustav Jung termasuk ke dalam psikologi sastra dan dapat digunakan untuk menganalisis setiap tokoh yang ada dalam karya sastra.

\section{Arketipe menurut perspektif Carl Gustav Jung}

Isi dari taraf tak sadar adalah arketipe. Arketipe dianggap sebagai tema universal yang memengaruhi tingkah laku manusia. Arketipe adalah bentuk pemikiran atau ide yang menjadi dasar pandangan kita, yang diproyeksikan pada pengalaman yang sedang kita alami. Menurut Jung manusia yang sehat berhubungan dengan alam tak sadar pribadi dan alam tak sadar kolektifnya, agar tidak mengalami berbagai gangguan jiwa. Di antara berbagai citra primordial yang dimiliki manusia, Jung mengatakan terdapat empat arketipe terpenting yaitu: Persona (topeng), Anima-animus, Bayangan (shadow), dan Self (diri).

\section{METODE PENELITIAN}

Metode yang digunakan dalam penelitian ini yaitu metode deskriptif kualitatif. Metode deskriptif merupakan metode penelitian yang bertujuan untuk menggambarkan keadaan atau status fenomena (Arikunto, 2010: 3). Moleong (2007: 9) mendefinisikan metode kualitatif yaitu pengamatan, wawancara, atau penelaahan dokumen. Metode kualitatif yang menggambarkan, mendeskripsikan, atau melukiskan keadaan subjek dan objek penelitian pada saat sekarang berdasarkan fakta-fakta apa adanya.

Metode kualitatif pada dasarnya memanfaatkan cara-cara penafsiran dengan menyajikannya dalam bentuk deskripsi yang bermaksud untuk memahami fenomena tentang apa yang dialami oleh subjek penelitian, misalnya perilaku, persepsi, motivasi, tindakan, dan lainnya. Penelitian ini untuk mendeskripsikan, mencatat, menganalisis, dan menginterpretasikan psikologi tokoh Agus Tubagus yang ada dalam naskah drama Pinangan. Sehubungan dengan itu, penulis menggunakan metode kualitatif sebagai bahan awal dalam pengkajian psikologi tokoh dalam naskah drama Pinangan karya Anton P. Chekhov saduran Jim Lim Suyatna Anirun.

\section{HASIL PENELITIAN DAN PEMBAHASAN}

. Dalam arketipe perspektif Carl Gustav Jung terdapat empat hal yang menunjukkan ciri kepribadian, namun penulis membatasi penelitian ini pada tiga aspek struktur 
kepribadian saja. Tiga struktur kepribadian tersebut adalah persona (topeng), shadow (bayangan), dan self (diri). Adapun pembahasan dari temuan tersebut sebagai berikut.

\section{Persona (topeng)}

Topeng di sini adalah suatu citra dan kesan yang ingin ditampilkan pada orang-orang yang ditemui (pencitraan). Topeng yang dimiliki seseorang sangatlah beragam, tergantung siapa orang yang ditemui dan ingin seperti apa citra yang ia tampilkan kepada orang tersebut. Secara garis besar topeng adalah seperti kedok untuk menampilkan suatu citra dan kesan yang ingin ditampilkan, topeng biasanya sangat berbeda dengan sifat asli orang tersebut. Seperti halnya topeng yang bisa dicopot dan dipakai, persona dapat dimanipulasi kapan pun orang tersebut mau. Persona berkaitan erat dengan psikologi seseorang. Seperti pada contoh dialog di bawah yang menunjukkan psikologi seseorang dilihat dari aspek persona:

(1) Oh, tidak Aku hanya akan mengunjungi Pak Rukmana Kholil yang baik. (Chekhov, 2006: 2).

Hal tersebut terlihat jelas menunjukkan persona Agus yang ditandai dengan jawaban sedemikian sopannya setelah disapa oleh Pak Rukmana Kholil, bahkan menyanjung Pak Rukmana Kholil yang diakhiri kata "yang baik". Di sini sangat jelas bahwa Agus ingin menampilkan citra dan kesan yang sopan, santun, dan ingin dilihat sebagai orang yang baik oleh Pak Rukmana.

\section{Shadow (bayangan)}

Psikologi seseorang dapat dilihat dari berbagai unsur, salah satunya adalah tingkah laku. Shadow adalah tingkah laku seseorang yang menampilkan kelemahan dan kekurangan seseorang, baik yang disadari ataupun yang tidak ia sadari. Bayangan seseorang cenderung menunjukkan sisi gelap atau sisi yang jahat dalam dirinya, pun menunjukkan aksi dan naluri yang wajar serta biasa-biasa saja yang setiap orang pasti memilikinya. Berikut data temuan mengenai shadow dalam naskah drama Pinangan karya Anton P. Chekhov:
(2) Begini soalnya. (MEMEGANG TANGANNYA SENDIRI) Aku mengunjungi Pak Rukmana Kholil yang baik, karena ada satu permintaan. Sudah lebih satu kali aku merasa sangat beruntung telah mendapatkan pertolongan dari Bapak yang selalu boleh dikatakan..., tapi aku, aku begitu gugup. Bolehkah aku minta segelas air, Pak Rukmana? Segelas air! (Chekhov, 2006: 2).

Shadow seseorang salah satunya adalah menunjukkan kelemahannya. Pada dialog kali ini Agus telah menunjukkan kelemahannya yang begitu gugup saat bertemu dan berbicara dengan Pak Rukmana Kholil. Karena begitu gugup, sampai-sampai Agus meminta segelah air kepada Pak Rukmana Kholil untuk ia minum agar menenangkan keadaannya yang sedang gugup.

Agus sedang menjelaskan maksud dan tujuan ia datang ke rumah Pak Rukmana Kholil. Agus menjelaskan dengan sopan dan santun, namun ditengah-tengah penjelasannya tersebut ia mulai gugup dan terlihat sangat tegang. Akhirnya Agus meminta air minum kepada Pak Rukmana Kholil untuk sekadar menenangkan perasaannya tersebut.

\section{Self (diri)}

Self adalah tujuan hidup seseorang yang mau tidak mau harus diterima karena sudah menjadi nasib. Tujuan hidup itu untuk mewujudkan diri yang sejati. Konflik dan pertentangan sudah tidak berfungsi lagi dalam hal ini, seseorang melakukan suatu hal berdasarkan kemauannya dan tidak lagi memikirkan baik atau buruknya. Pada taraf ini seseorang mengalami keseimbangan dalam dirinya, dia merasa utuh dan stabil. Pengalaman-pengalaman religius sejati merupakan bentuk pengalaman paling dekat dengan self. Karena self adalah yang paling melekat dengan keikhasan seseorang, maka self berhubungan erat juga dengan psikologi yang ada pada diri seseorang. Seperti pada salah satu dialog dalam naskah drama Pinangan yang menunjukkan psikologi seseorang dilihat dari aspek self:

(24) (MULAI HIDUP) Berburu rusa? Eeee... Aku berharap berburu ayam liar setelah panen selesai, Ratna Rukmana yang baik. Tapi 
sudahkah kau mendengar betapa jeleknya nasib si Belang, anjingku kau kenal dia? ... Kakinya lumpuh... (Chekhov, 2006: 15).

Seperti pada dialog di atas menunjukkan self Agus yang kembali hidup dan merasakan ketenangan setelah Ratna Rukmana mengajaknya untuk berburu rusa. Agus mulai merasakan tujuan hidup yang selama ini ia dambakan, tak ada lagi perdebatan soal tanah lapangan. Agus berbincang manja dengan Ratna Rukmana Kholil, saling curhat perihal anjing yang ia punyai.

\section{SIMPULAN}

Berdasarkan hasil penelitian Analisis Psikologi Tokoh Dalam Naskah Drama Pinangan Karya Anton P. Chekhov Saduran Jim Lim Suyatna Anirun Dengan Pendekatan Psikologi Analitis Carl Gustav Jung Serta Implikasinya Terhadap Pembelajaran Bahasa Indonesia di SMA, penulis dapat merumuskan simpulan sebagai berikut:

1. Dari hasil analisis, psikologi tokoh utama dalam naskah drama Pinangan dapat dikaji dengan teori psikologi analitis yang telah dikemukakan oleh Carl Gustav Jung. Hal tersebut diperkuat dengan temuan data psikologi tokoh dalam pribadi tokoh utama berupa tiga aspek. Tiga aspek psikologi tersebut di antaranya, Persona (P) ditunjukkan dari tingkah laku tokoh utama di depan orang-orang yang ia hormati dan cintai. Tokoh utama selalu ingin memberikan kesan dan citra yang baik di hadapan orang-orang yang ia hormati dan cintai, itu karena tokoh utama ingin meraih tujuan hidupnya yaitu menikah dengan wanita yang ia cintai. Shadow (SD) ditunjukkan dengan perilaku tokoh utama yang selalu memunculkan perilaku buruknya, itu karena ia tidak bisa mengontrol emosi dan menjadikan hal tersebut sebagai kekurangan serta kelemahan yang ada pada diri tokoh utama. Self (S) bentuk dari perilaku yang ditunjukkan oleh tokoh utama yaitu ketika ia tak lagi memikirkan hal baik dan buruk yang ada, cenderung melupakan hal-hal buruk yang sebelumnya terjadi, itu di karenakan tujuan hidupnya telah tercapai sepenuhnya serta hanya gembira dan bahagia yang tokoh utama pikirkan.

2. Jumlah data keseluruhan yang ditemukan sebanyak 30 data yang terbagi ke dalam beberapa aspek psikologi, di antaranya, ditemukan aspek Persona sebanyak 10 data. Shadow sebanyak 18 data. Self sebanyak 2 data. Dengan demikian, dapat ditarik simpulan bahwa aspek psikologi tokoh utama pada naskah drama Pinangan karya Anton P. Chekhov saduran Jim Lim Suyatna Anirun yang paling dominan yaitu aspek shadow dan persona. Hal ini terjadi karena konflik cerita yang tersaji dalam naskah drama tersebut yaitu mengenai kisah cinta dan perdebatan, serta tak ada yang mau menurunkan ego masing-masing dalam menghadapi setiap permasalahan yang datang. Psikologi tokoh utama yang paling dominan muncul yaitu ketika perdebatan hak kepilikan tanah lapangan dan adu kehebatan anjing masing-masing. Psikologi kedua yang sering muncul pada diri tokoh utama yaitu pada saat tokoh utama ingin meraih tujuan hidupnya, ia selalu memunculkan topeng yang ingin ia tampilkan di depan orang-orang yang ia hormati dan cintai. Kenyataan dari semuanya adalah setiap orang memanglah memiliki bayangan dan topengnya masing-masing yang menunjukkan psikologi orang tersebut seperti tokoh utama dalam naskah drama Pinangan karya Anton P. Chekhov. Selain itu, penelitiaan ini dapat diimplikasikan dalam pembelajaran bahasa Indonesia. Kemudian dalam naskah drama Pinangan banyak mengandung nilainilai positif yang dapat diambil, seperti sikap sopan santun dan pantang menyerah yang ada dalam diri Agus Tubagus.

\section{REFERENSI}

Aminuddin. 2009. Pengantar Apresiasi Karya Sastra. Bandung: Sinar Baru Algensindo.

Endraswara, Suwardi. 2008. Metode Penelitian Psikologi Sastra. Yogyakarta: Media Pressindo. 
Hasanuddin. 2015. Drama Karya dalam Dua Dimensi Kajian Teori, Sejarah, dan Analisis. Bandung: Angkasa.

Hawa, Masnuatul. 2017. Teori Sastra. Yogyakarta: Deepublish.

Jung, Carl Gustav. 2018. Diri Yang Tak Ditemukan. Terjemahan oleh Rani Rahmanillah. Yogyakarta: IRCISoD.

Kosasih, E. 2003. Ketatabahasaan dan Kesusastraan. Bandung: Yramada Widiya.

Minderop, Albertine. 2018. Psikologi Sastra: Karya Sastra, Metode, Teori, dan
Contoh Kasus. Edisi 2. Cetakan 5. Jakarta: Yayasan Pustaka Obor Indonesia.

Moleong, Lexy J. 2007. Metodologi Penelitian Kualitatif: edisi Revisi. Bandung: PT. Remaja Rosda Karya.

Poerwadarminta, W.J.S. 2012. Kamus Umum Bahasa Indonesia. Jakarta: Balai Pustaka.

Suryabrata, Sumadi. 2014. Psikologi Pendidikan. Jakarta: Rajagrafindo Persada. 